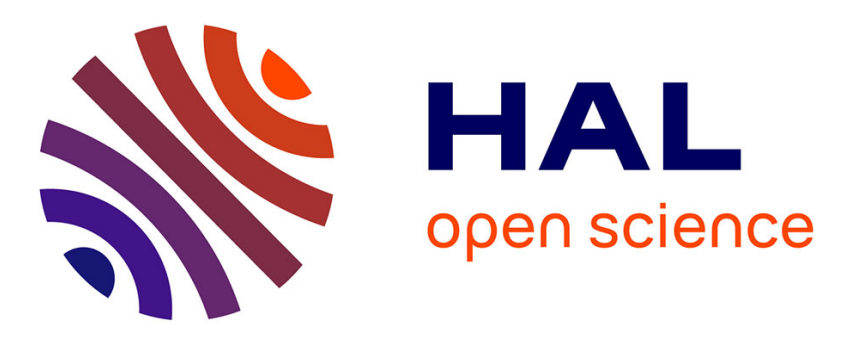

\title{
Mass deacidification of papers and books: V. Fungistatic properties of papers treated with aminoalkylalkoxysilanes
}

Malalanirina Sylvia Rakotonirainy, Anne-Laurence Dupont, Bertrand Lavédrine, Stéphane Ipert, Hervé Cheradame

\section{To cite this version:}

Malalanirina Sylvia Rakotonirainy, Anne-Laurence Dupont, Bertrand Lavédrine, Stéphane Ipert, Hervé Cheradame. Mass deacidification of papers and books: V. Fungistatic properties of papers treated with aminoalkylalkoxysilanes. Journal of Cultural Heritage, 2008, 9 (1), pp.54-59. 10.1016/j.culher.2007.12.002 . hal-01491225

\section{HAL Id: hal-01491225 \\ https://hal.science/hal-01491225}

Submitted on 22 Mar 2017

HAL is a multi-disciplinary open access archive for the deposit and dissemination of scientific research documents, whether they are published or not. The documents may come from teaching and research institutions in France or abroad, or from public or private research centers.
L'archive ouverte pluridisciplinaire HAL, est destinée au dépôt et à la diffusion de documents scientifiques de niveau recherche, publiés ou non, émanant des établissements d'enseignement et de recherche français ou étrangers, des laboratoires publics ou privés. 


\title{
Mass deacidification of papers and books: V. Fungistatic properties of papers treated with aminoalkylalkoxysilanes
}

\author{
Malalanirina Sylvia Rakotonirainy ${ }^{\mathrm{a}}$, Anne-Laurence Dupont ${ }^{\mathrm{a}, *}$, Bertrand Lavédrine ${ }^{\mathrm{a}}$, \\ Stéphane Ipert ${ }^{\mathrm{b}}$, Hervé Cheradame ${ }^{\mathrm{c}}$ \\ ${ }^{a}$ Centre de Recherche sur la Conservation des Collections, UMR CNRS 7188, Muséum National d'Histoire Naturelle, Ministère de la Culture et de la \\ Communication, 36 rue Geoffroy Saint-Hilaire, 75005 Paris, France \\ ${ }^{\mathrm{b}}$ Centre de Conservation du Livre, 18 rue de la Calade, 13200 Arles, France \\ ${ }^{\mathrm{c}}$ Laboratoire Matériaux Polymères aux Interfaces, UMR CNRS 7581, Université d'Evry, Bld F. Mitterrand, 91025 Evry, France
}

Received 5 April 2007; accepted 6 September 2007

\begin{abstract}
A new process using aminoalkylalkoxysilanes (AAAS) was developed recently for paper and book mass deacidification. This process is entirely novel in that, besides deacidifying, it also improves the mechanical properties of paper. In the present article, the properties of inhibition of fungal growth of the treated papers are investigated. It was found that the AAAS tested acted as surface-active antifungal agents when introduced in the paper, significantly reducing the growth of Aspergillus niger and Paecilomyces variotii, two fungal species commonly found in storage areas of libraries and archives. The AAAS which seemed the most efficient in preventing the fungal development was 3-aminopropylmethyldimethoxysilane (AMDES), functionalised with a primary amine. The effect was significant in the different papers tested which demonstrated the protection against the proliferation of filamentous fungi in vitro for papers treated with AMDES. The higher concentration of AMDES inside the paper proved to be the most effective. The highest efficiency was reached for AAAS uptakes around 6\%. At this concentration the sporulation of the two strains was inhibited and the development of $A$. niger mycelia was highly reduced.
\end{abstract}

(C) 2007 Elsevier Masson SAS. All rights reserved.

Keywords: Deacidification; Paper; Aminoalkylalkoxysilanes; Biodeterioration; Fungistatic activity

\section{Introduction and research aims}

Mass deacidification is a chemical process involving the neutralisation of the acids present in the paper and the deposition of an alkaline buffer to prevent, or at least retard, further acidification. Several processes have been developed and proposed in the past three decades but mass deacidification remains a controversial issue, and professionals at libraries and archives are still divided about its usefulness [1]. The main drawback attributed to current processes is that besides the neutralisation and buffering action, they impart no physical strengthening of the paper. Indeed, books and documents

\footnotetext{
* Corresponding author. Tel.: +331407953 07; fax: +33140795312.

E-mail address: aldupont@mnhn.fr (A.-L. Dupont).
}

acidify with time but also become brittle and unusable. In addition to deacidification they require strengthening to recover the mechanical resistance to allow further handling. The need for a deacidification technique that would solve the acidity problem of aged items printed on paper by neutralisation and alkaline reserve deposition, as well as introduce physical strengthening is undeniable. For this reason a novel process based on impregnation with aminoalkylalkoxysilanes (AAAS) was recently developed $[2,3]$. This technique, in which aminoalkylalkoxysilanes dissolved in an appropriate solvent are deposited onto the cellulosic fibres where they can react and polycondensate, was shown to produce paper with enhanced mechanical resistance. The treatment brought both an immediate improvement of the mechanical properties of the treated material as well as a continuous effect upon long-term storage. 
Upon ageing, mechanical resistance was significantly improved, as shown by accelerated ageing experiments [3]. The necessity to ensure the longevity of treated items led the authors to the question of addressing other sources of paper decay besides acidity, such as biological attacks, and their possible resistance to it. Indeed, the degradation of documents by the microorganisms and more particularly filamentous fungi is a recurring problem in libraries and archives repositories. Mould requires an organic food source to develop, and cellulose-containing materials such as paper provide a good substrate for their growth. The damage is irreversible and in the long-term could cause the complete destruction of the documents. When a contamination by fungi is actively established in a repository, it can be difficult to eradicate the microorganisms' growth. The only efficient disinfection process currently available for documents involves the use of ethylene oxide and the aerial disinfection of the atmosphere in the storage area. Such interventions are painstaking, time-consuming and expensive. The prevention of mould growth is therefore a necessary task and a true challenge for curators and collection keepers. A careful control of the environment and regular cleaning are recommended in order to avoid biocontamination. However, such preventive measures are not always sufficient, especially in the case of flood disasters. For several decades, there has been an increased interest in developing materials with high chemical or mechanical resistance or specific protective properties against environmental attack such as biological degradation [4-6]. This has often been tackled by developing functionalised materials' surfaces. A surface-active antifungal agent can be obtained, for instance, by bonding surfaces or materials with a reactive silane coupling agent [7]. Alkoxysilanes have been widely used to transform various materials into active antimicrobial surfaces [8-10]. The impregnation of documents with such compounds could conceivably achieve prevention against biological attack. As the new compounds proposed for mass deacidification and reinforcement of paper documents are based on alkoxysilanes, it was decided to investigate their possible protective action against fungal growth.

\section{Materials and methods}

\subsection{Deacidification treatment solutions and methodology}

The treatment process has been extensively described elsewhere [2] and the main characteristics are recalled here. The items are impregnated for $10 \mathrm{~min}$ by immersion in a $10 \%$ $(\mathrm{wt} / \mathrm{wt})$ solution of AAAS in a silicone based solvent, at room temperature. These solvents have been shown to be well adapted to the deacidification treatment [11]. The drying is effected in an oven under vacuum at room temperature unless otherwise stated. The AAAS uptake (expressed in \% wt/ wt) is measured by weighing the items before and after treatment with the approximation that the moisture content at constant temperature and humidity was not significantly modified by the treatment.
The various AAAS compounds assayed were:

- 2-aminoethyl-3-aminopropylmethyldimethoxysilane (AA MDS, ABCR Gelest)

- 3-aminopropylmethyldiethoxysilane (AMDES, ABCR Gelest)

- $N, N$-dimethylaminopropyltrimethoxysilane (DMATMS, ABCR Gelest)

- 4-amino-3,3-dimethylbutyltrimethoxysilane (ADBTMS, General Electric)

These compounds were dissolved in hexamethyldisiloxane (HMDS, ABCR Gelest) or tetramethylsilane (TMS, ABCR Gelest).

Table 1 indicates the multiple combinations of AAAS/solvent/paper tested as well as the percent uptake of AAAS achieved in the papers after treatment and drying.

The treated paper showing the best antifungal activity was also tested at different levels of uptake to determine the minimal concentration needed to obtain a significant inhibitory effect on the selected fungal strains. It was also used at this concentration for the ageing experiments.

\subsection{Biological assays}

The antifungal activity of the different treated papers was evaluated using a protocol based on the paper disc method proposed by Bauer et al. [12] with Aspergillus niger van Tieghem (myc7) and Paecilomyces variotii Bainier (myc28), both from the fungal collection of the Centre de Recherche sur la Conservation des Collections (CRCC). The strains were isolated from mouldy archives documents and chosen as representative among the most frequent fungal strains found on contaminated documents. The strains, maintained on malt-yeast extract-agar (MEA), were used either individually or in a mix (1:1). The spores' suspensions were prepared in deionised water, adding a microdrop of Tween 80, a non-ionic surfactant, in order to prevent spores aggregation. One $\mathrm{ml}$ of the spores' suspension, adjusted to a concentration of $1 \times 10^{6}$ spores $\mathrm{ml}^{-1}$ was spread on the MEA medium surface previously poured in $90-\mathrm{mm}$ diameter Petri dishes. Specimens of paper, $2.5 \mathrm{~cm}$ in diameter that had been previously treated with the different deacidification solutions as well as control papers untreated, were immersed during a few seconds in the spores' suspension, and immediately placed in the centre of the inoculated Petridishes. The plates were then incubated for 21 days at $25^{\circ} \mathrm{C}$. Untreated paper discs were placed on non-inoculated media as control as the paper samples were not sterilised before use, and they could possibly contain naturally deposited fungal spores. The effect of the different products and their concentration were evaluated by the level of visible growth on the paper samples. Untreated, treated and naturally aged papers were compared. The levels of growth were categorised on a scale ranging from 0 to 5 according to the growth intensity. The different scale levels proposed are the following: (0) absence of growth, (1) very low mycelial growth with very sparse sporulation, (2) low mycelial growth with dispersed sporulation, (3) low mycelial growth with good sporulation, (4) high mycelial 
Table 1

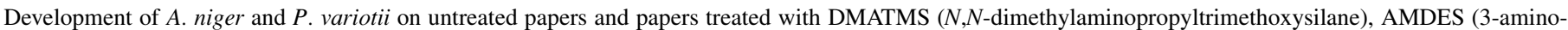

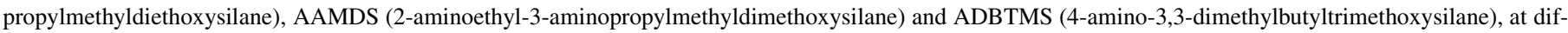
ferent concentrations so as to obtain various uptakes (after 21 days of incubation at $25^{\circ} \mathrm{C}$ )

\begin{tabular}{|c|c|c|c|c|c|c|c|c|c|c|c|c|c|c|}
\hline \multirow[b]{3}{*}{ Paper 1} & \multirow{3}{*}{$\begin{array}{l}\text { AAAS/solvent } \\
\text { Untreated control }\end{array}$} & \multirow{3}{*}{$\begin{array}{l}\text { AAAS uptake } \% \\
(w t / w t) \\
0\end{array}$} & \multicolumn{12}{|c|}{ Growth level } \\
\hline & & & \multicolumn{4}{|c|}{ P. variotii } & \multicolumn{4}{|c|}{ A. niger } & \multicolumn{4}{|c|}{ Mix } \\
\hline & & & 5 & 5 & 5 & 5 & 5 & 5 & 5 & 5 & 5 & 5 & 5 & 5 \\
\hline & DMATMS/HMDS & 1.3 & 4 & 5 & 4 & 4 & 5 & 4 & 4 & 4 & 4 & 4 & 4 & 4 \\
\hline & AMDES/TMS & 2.2 & 4 & 3 & 3 & 3 & 3 & 4 & 3 & 3 & 3 & 3 & 3 & 3 \\
\hline & AMDES/HMDS & 6.4 & 1 & 1 & 1 & 1 & 2 & 2 & 2 & 2 & 1 & 1 & 2 & 1 \\
\hline & AMDES/TMS & 6.9 & 1 & 2 & 1 & 1 & 2 & 2 & 3 & 2 & 1 & 1 & 1 & 1 \\
\hline & AMDES/TMS & 9.6 & 1 & 1 & 1 & 1 & 3 & 2 & 2 & 2 & 1 & 1 & 1 & 1 \\
\hline & AAMDS/HMDS & 11.5 & 3 & 3 & 3 & 3 & 3 & 3 & 3 & 3 & 3 & 3 & 3 & 3 \\
\hline & ADBTMS/TMS & 6.3 & 2 & 2 & 1 & 2 & 2 & 1 & 2 & 2 & 2 & 2 & 2 & 2 \\
\hline \multirow[t]{4}{*}{ Paper 2} & Untreated control & 0 & 5 & 5 & 5 & 5 & 5 & 5 & 5 & 5 & 5 & 5 & 5 & 5 \\
\hline & DMATMS/HMDS & 8.1 & 5 & 4 & 4 & 4 & 4 & 4 & 4 & 4 & 4 & 4 & 4 & 4 \\
\hline & AMDES/HMDS & 6.3 & 1 & 1 & 2 & 1 & 1 & 1 & 2 & 1 & 1 & 1 & 2 & 1 \\
\hline & AMDES/TMS & 11.4 & n.d. ${ }^{\mathrm{a}}$ & n.d. & n.d. & n.d. & n.d. & n.d. & n.d. & n.d. & 2 & 2 & 2 & 2 \\
\hline \multirow[t]{3}{*}{ Paper 3} & Untreated control & 0 & 5 & 5 & 5 & 5 & 5 & 5 & 5 & 5 & 5 & 5 & 5 & 5 \\
\hline & AAMDS/HMDS & 12.7 & 3 & 1 & 3 & 3 & 3 & 3 & 3 & 3 & 3 & 1 & 3 & 3 \\
\hline & ADBTMS/HMDS & 7.1 & 2 & 2 & 2 & 2 & 2 & 2 & 2 & 2 & 2 & 2 & 2 & 2 \\
\hline
\end{tabular}

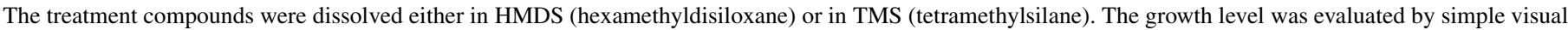


control) and " 0 " to the absence of growth. The numbers in the four columns correspond to the four replica measurements done in each case.

a n.d., not determined.

growth with dispersed sporulation, and (5) high sporulation, similar to that on untreated papers. The downy mycelia and pigmented conidia were observed directly with the naked eye.

The reproducibility of the assays was tested by duplicating each sample (paper/treatment/fungal strain), and the repeatability by performing a duplicate experiment on a different day.

\subsection{Papers tested}

In order to evaluate the possible influence of the origin of the paper in relation to its resistance to fungal agents, three papers were used:

- paper 1, a modern paper made of pure cellulose (cotton linters)

- paper 2, originating from a book printed in 1923, made of $30 \%$ unbleached sulphite pulp (spruce) and $70 \%$ mechanical pulp (softwood)

- paper 3, originating from a book printed in 1924, made of $40 \%$ unbleached sulphite pulp (spruce), $40 \%$ mechanical pulp (aspen), and 20\% mechanical pulp (spruce)

\subsection{Accelerated ageing}

In order to evaluate the antifungal effect of the AAAS treatment on the long-term, samples of paper 1 were submitted to an accelerated ageing using heat and humidity (28 days at $80{ }^{\circ} \mathrm{C}$ and $65 \% \mathrm{RH}$ ) in an environmental chamber (Heraeus Vöstch HC0020) according to the standard ISO 5630-3:1996.

\subsection{Mechanical testing measurements}

To evaluate the mechanical properties of the papers treated with different concentration of the most effective AAAS, the following parameters were measured:

- tensile breaking resistance, according to standard NF: Q03-004 July 1986, using Adamel Lhomargy DY-20B instrument

- folding endurance, according to standard ISO 5626: 1993, using Tinius Olsen MIT Folding Endurance Tester

- dry and wet zero span tensile strength, according to standard ISO 15361:2000, using Pulmac TS-100 instrument

These tests were carried out on paper 1 only.

\section{Results}

\subsection{Biological activity of the AAAS}

All the AAAS displayed an inhibitory action on the fungal growth of $A$. niger and $P$. variotii (Table 1). Additionally, no inhibition zone around the paper disc samples was noted, which indicated that there was no diffusion of the AAAS from the sample into the agar medium. This indicates that the aminosilane compounds are well anchored in the papers fibre bed. This observation corroborates previous observations that after the treatment not only the alkoxy functions could be partially hydrolysed (with possible hydrogen bonding between the AAAS and the cellulose), but also that the treatment products oligomerised and linked with the cellulosic substrate, 
possibly through covalent bonds [2]. The protective efficiency does not seem to be solvent dependent. Indeed, the solvents are extracted from the papers after the AAAS treatment by drying under vacuum, thus no difference is expected. This is illustrated in Fig. 1. No difference in the behaviour of the two strains was noted, even though when tested individually $P$. variotii appeared, in some cases, slightly more sensitive to AAAS than A. niger.

Among the compounds tested, AMDES displayed the larger inhibitory action on fungal growth, reducing both the mycelia development and the sporulation. This was obtained with an AAAS uptake between $6 \%$ and $7 \%$ (Table 1). Higher concentrations did not improve the antifungal efficiency, the level of growth with an AMDES uptake of $9.6 \%$ in the paper was similar to that obtained with lower uptakes. Table 1 also shows that ADBTMS provided a good antifungal protection to the treated papers.

Comparing papers 1 and 2 it can also be concluded that most likely the nature of the paper, i.e. the pulp composition, does not noticeably influence the protection brought by the use of the various AAAS.

An interesting observation can be made regarding the class of the amine function of the AAAS used. Table 1 shows that a tertiary amine aminosilane (DMATMS) did not impart to paper 2 sufficient protection, despite an important uptake of $8.1 \%$. The low efficiency of AAMDS despite a high uptake is more surprising (Table 1, papers 1 and 3). A slightly lower efficiency of ADBTMS compared to that of AMDES at similar uptakes can also be noted (Table 1, papers 1 and 3 ). The reason for this difference is not yet clear, but could be related to the type of group bearing the primary amine, which is a n-propyl group in the case of AMDES. This particular point is currently under investigation.

According to these results, AMDES was selected for more in depth investigation in further experiments.

\subsection{Effect of the concentration of AMDES on the fungistatic activity}

Results clearly showed that the inhibitory effect of AMDES on the growth of the two fungal strains increased with the concentration of the compound, up to a certain point (Table 2, Fig. 2). Below 5.6\%, the protective action of the AMDES remained relatively weak. Whereas all concentrations above 5.6\% AMDES yielded approximately the same-high-level of growth inhibition.

\subsection{Effect of AMDES treatment on the mechanical properties of paper}

It is worth recalling that the treatment process had been designed for the mass deacidification of books and paper-based documents, and that besides depositing an alkaline reserve, it aims at imparting a strengthening effect to the treated materials. For this reason, and in order to prove that the AAAS treatment provides multiple protection benefits to paper, mechanical properties of paper 1 treated with increasing concentrations of AMDES were measured. Results showed that higher uptakes of AMDES did not necessarily induce an increase of the dry breaking length, but rather improved elongation at break and folding endurance (Table 3). A low uptake did not modify significantly the initial mechanical characteristics, as shown with samples with $0.7 \%$ uptake. As expected from previous studies, the improvement of the mechanical properties were significant for samples with an uptake of at least $2.8 \%$. However, it can be noted that while folding endurance improved, the tensile resistance was unmodified. In the various experiments carried out, it was observed that the increase of tensile resistance, and tensile energy absorption (TEA), was to be attributed mainly to the nature of the AAAS [2], and to some extent also to the ageing state of the papers [3].
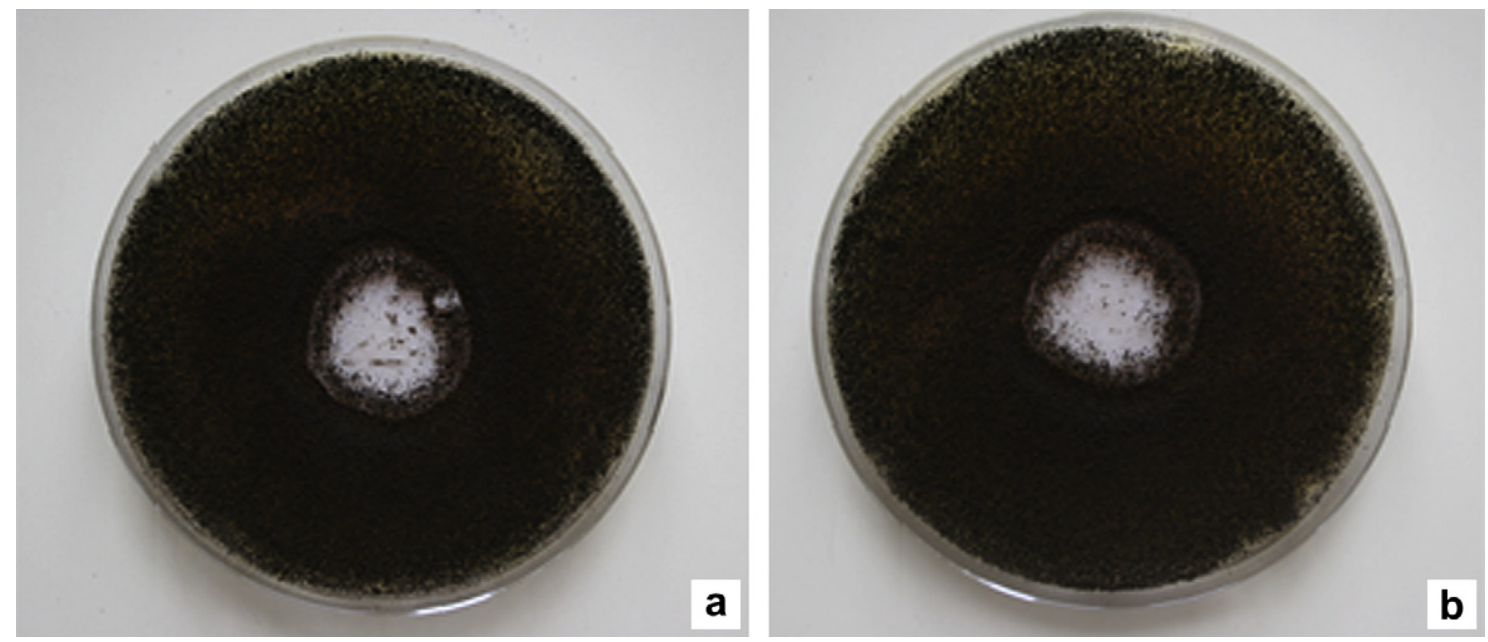

Fig. 1. Development of A. niger and P. variotii (mix) on paper 1 treated with (a) AMDES 6.4\% uptake (wt/wt) in HMDS, growth level 1; and (b) AMDES 6.9\% uptake (wt/wt) in TMS, growth level 1. 
Table 2

Development (growth level estimated as above, see caption in Table 1) of $A$. niger and $P$. variotii (in mix) on paper 1 treated with AMDES in HMDS at different concentrations so as to obtain various uptakes (21 days of incubation at $25^{\circ} \mathrm{C}$ )

\begin{tabular}{lllll}
\hline AMDES uptake $\%(w t / w t)$ & \multicolumn{4}{l}{ Growth level } \\
\hline 0 (Control) & 5 & 5 & 5 & 5 \\
0.7 & 4 & 4 & 3 & 4 \\
2.8 & 3 & 3 & 3 & 3 \\
5.6 & 1 & 1 & 1 & 1 \\
6.4 & 1 & 1 & 2 & 1 \\
9.6 & 1 & 1 & 1 & 1 \\
\hline
\end{tabular}

The numbers in the four columns correspond to the four replica measurements done in each case.

From the experiments reported here, and according to previous work carried out [2,3], it is clear that the deacidification treatment, besides alkaline buffer deposition, paper strengthening and a significant resistance to ageing, was also able to confer fungistatic properties to the treated papers.
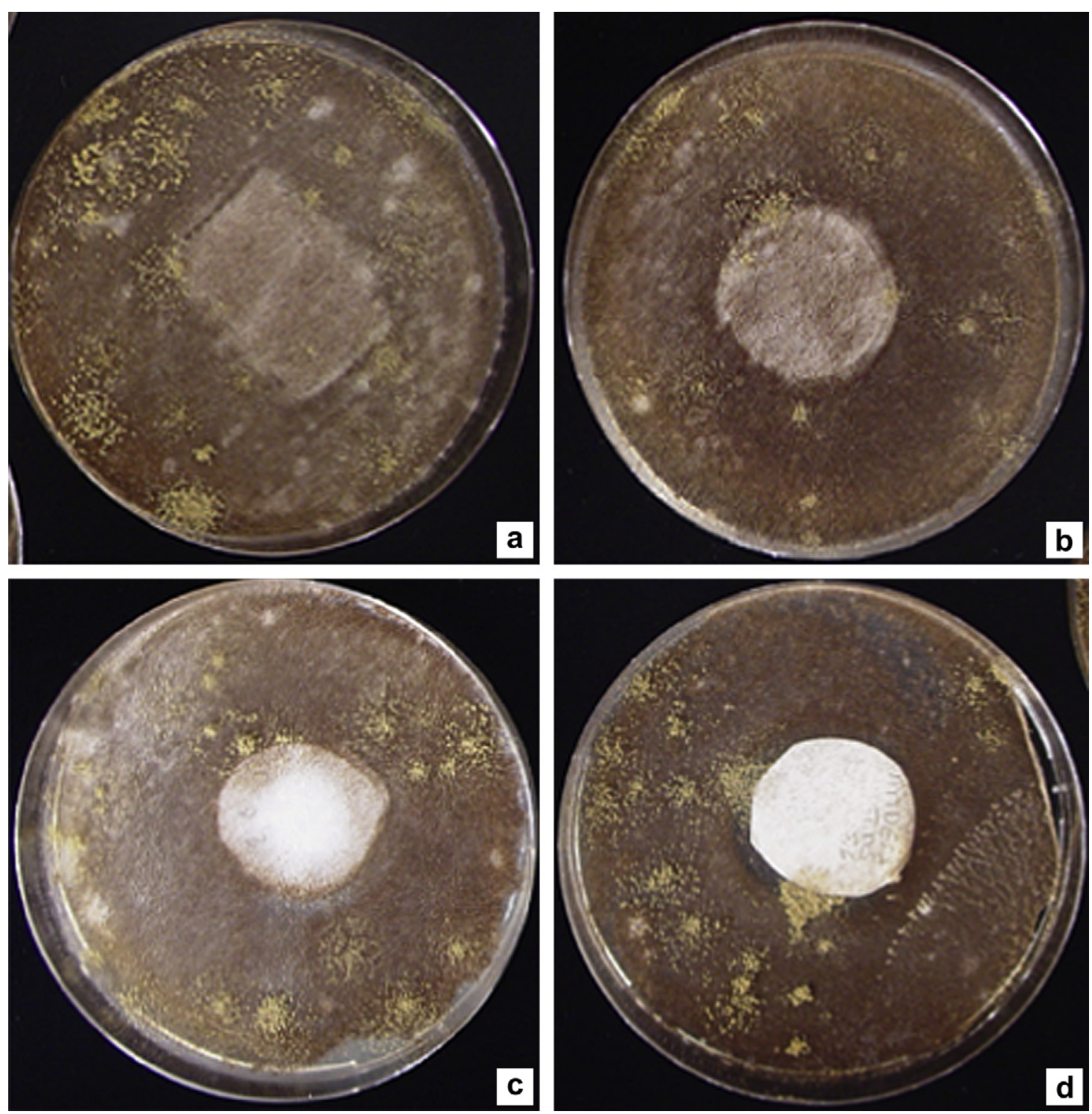

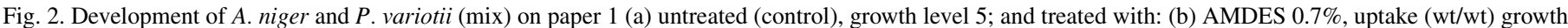
level 4; (c) AMDES 2.8\%, uptake (wt/wt) growth level 3; (d) AMDES 5.6\%, uptake (wt/wt) growth level 1.
Table 3

Mechanical properties of paper 1 treated with AMDES at different concentrations so as to obtain various uptakes

\begin{tabular}{llllll}
\hline $\begin{array}{l}\text { AMDES } \\
\text { uptake } \% \\
(\mathrm{wt} / \mathrm{wt})\end{array}$ & $\begin{array}{l}\text { Breaking } \\
\text { length } \\
(\mathrm{m})\end{array}$ & $\begin{array}{l}\text { Elongation } \\
\text { at break } \\
(\%)\end{array}$ & $\begin{array}{l}\text { Folding } \\
\text { endurance } \\
\text { (no folds) }\end{array}$ & $\begin{array}{l}\text { Zero span } \\
\text { breaking } \\
\text { length, dry } \\
\text { state }(\mathrm{m})\end{array}$ & $\begin{array}{l}\text { Zero span } \\
\text { breaking } \\
\text { length, wet } \\
\text { state }(\mathrm{m})\end{array}$ \\
\hline 0 & 2700 & 2.1 & 72 & 8100 & 5800 \\
0.7 & 2600 & 2.2 & 73 & 8200 & 5500 \\
2.8 & 2600 & 2.4 & 89 & 8800 & 5500 \\
5.6 & 2600 & 2.5 & 117 & 8900 & 5600 \\
6.4 & 2700 & 2.7 & 183 & 8300 & 5300 \\
\hline
\end{tabular}

\subsection{Effect of accelerated ageing of paper on the fungistatic activity of ADBTMS}

Paper 1 treated with ADBTMS at a concentration of $9.3 \%$ (uptake of $5.6 \%(\mathrm{wt} / \mathrm{wt})$ ) was submitted to the accelerated heat/humidity ageing. Being deprived of hydrogen atoms in 
Table 4

Development (growth level estimated as above, see caption in Table 1) of $A$. niger and $P$. variotii (mix) on paper 1 treated with ADBTMS (5.6\%, uptake $(\mathrm{wt} / \mathrm{wt}))$ before and after accelerated ageing $\left(28\right.$ days at $\left.80^{\circ} \mathrm{C}, 65 \% \mathrm{RH}\right)$

\begin{tabular}{lllllllll}
\hline & Unaged & \multicolumn{7}{c}{ Aged } \\
\hline A. niger & 1 & 1 & n.d. & n.d. & 2 & 2 & n.d. & n.d. \\
$P$. variotii & 2 & 2 & n.d. & n.d. & 3 & 3 & n.d. & n.d. \\
Mix & 1 & 1 & 1 & 1 & 3 & 3 & 2 & 3 \\
\hline
\end{tabular}

The numbers in the four columns correspond to the four replica measurements done in each case.

${ }^{a}$ n.d., not determined.

the beta position of the amino group, thus undergoing no deamination during ageing, ADBTMS is supposed to be more resistant to heat/humidity ageing than other AAAS compounds [3]. Paper samples were inoculated with a spores' suspension of $A$. niger and $P$. variotii individually or in mixture (Table 4). After 21 days of incubation, mycelium growth accompanied by a slight sporulation was visible on the aged papers whereas on the unaged papers, even though mycelia were present, no sporulation was noticed. Papers treated with AAAS and subsequently aged appeared somewhat less resistant to fungal proliferation than unaged treated papers.

\section{Conclusion}

The sensitivity to mould contamination of papers treated with different deacidification agents based on aminoalkylalkoxysilane, were evaluated using $A$. niger and $P$. variotii. As a general appraisal, the different AAAS tested provided efficient protection against the growth of the microorganisms, with a clear fungal inhibiting power. 3-Aminopropyltmethyldiethoxysilane (AMDES) was the most effective, showing the highest fungi inhibitory activity. This effect increased with increasing AAAS uptake in the papers, up to a certain percentage. A concentration of $5.6 \%$ significantly decreased the development of the two fungal strains tested. However, at higher concentrations, no further inhibition was obtained.

This work clearly demonstrated that besides deacidification and reinforcement, the treatment of documents with aminoalkylalkoxysilanes (AAAS) imparts antifungal properties to the paper. This is a great additional asset of the newly proposed mass treatment, as current processes in use for libraries and archives can only offer a deacidification action. The new mass deacidification treatment additionaly increases the longevity of paper by imparting mechanical reinforcement and fungal growth resistance, thus representing a completely novel approach to cultural heritage preservation.

\section{Acknowledgements}

The General Electric Company is gratefully acknowledged for providing the ADBTMS. Dr E. Rousset is also warmly thanked for the paper fibres analysis. This work has been partly supported by the CNRS program "Matériaux" 2004, section "Matériaux multifonctionnels à structure hiérarchique".

\section{References}

[1] A. Blüher, G. Grossenbacher (Eds.), Save paper! Mass deacidification. Today's experiences-Tomorrow's perspectives, 15-17 February 2006, Swiss National Library, Bern, Switzerland, 2006216 pp.

[2] S. Ipert, E. Rousset, H. Cheradame, Mass deacidification of papers and books. III-Study of a paper strengthening and deacidification process with aminoalkyalkoxysilanes, Restaurator: International Journal for the Preservation of Library and Archival Material 26 (2005) 250-264.

[3] S. Ipert, A.-L. Dupont, B. Lavédrine, P. Bégin, E. Rousset, H. Cheradame, Mass deacidification of papers and books. IV-A study of papers treated with aminoalkyalkoxysilanes and their resistance to ageing, Polymer Degradation and Stability 91 (2006) 3448-3455.

[4] A.J. Isquith, E.A. Abbott, P.A. Walters, Surface-bonded antimicrobial activity of an organosilicon quaternary ammonium chloride, Applied Microbiology 24 (1972) 859-863.

[5] Y. Endo, T. Tani, M. Kodama, Antimicrobial activity of tertiary amine covalently bonded to a polystyrene fiber, Applied and Environmental Microbiology 53 (1987) 2050-2055.

[6] T. Ravikumar, H. Murata, R.R. Koepsel, A.J. Russell, Surface-active antifungal polyquaternary amine, Biomolecules 7 (2006) 2762-2769.

[7] K.L. Mittal (Ed.), Silanes and Other Coupling Agents Vol. 2 (2000).

[8] A. Kanazawa, T. Ikeda, T. Endo, Polymeric phosphonium salts as a novel class of cationic biocides. VI: Antibacterial activity of fibers surfacetreated with phosphonium salts containing trimethoxysilane groups, Journal of Applied Polymer Science 52 (1994) 641-647.

[9] S. Donath, H. Militz, C. Mai, Wood modification with alkoxysilanes, Wood Science and Technology 38 (2004) 5-566.

[10] C. Mai, H. Militz, Modification of wood with silicon compounds. Treatment systems based on organic silicon compounds-a review, Wood Science and Technology 37 (2004) 453-462.

[11] Battelle-Institut, German patent No. DE 4104515 C1, Canadian patent No. 2060926.

[12] A.W. Bauer, W.M. Kirby, J.C. Sherris, M. Turck, Antibiotic susceptibility testing by a standardized single disk method, Am. J. Clin. Pathol. 45 (1966) 493-496. 